\title{
EDITORIAL
}

Weihe HUANG, Chunfang LU, Dongping FANG

\section{Special issue: City and infrastructure engineering and management}

(C) Higher Education Press 2020

Urban and infrastructure systems are essential for the sustainable development of cities worldwide because they play a fundamental role in the provision of essential services, such as transport, communication, and health care, to support the basic livelihood of residents. With the rapid growth in the world's population and urbanization, especially in China, an increasing number of large-scale projects, megaprojects, super projects, complex engineering systems, urban systems, supercities, and urban agglomerations, which have ever-increasing structural and functional scales and complexities, are seen worldwide. Consequently, the planning, engineering, and operation of cities and infrastructure are faced with various emerging management challenges that stem from the need for new theories, models, and technologies to build efficient, affordable, and resilient urban and infrastructure systems.

An increasing number of studies related to the engineering and management of cities and infrastructure have been conducted in recent years to develop and propose various methodologies and tools that aim to address the aforementioned challenges.

This special issue in Frontiers of Engineering Management intends to provide an opportunity for exploring new ideas and disseminating the latest advancements on the theme "City and Infrastructure Engineering and Management". It offers researchers an opportunity to address prominent challenges pertaining to the understanding, analysis, and improvement of the engineering and management of cities and infrastructure.

He et al. investigated the critical success factors of construction megaproject management by studying three megaprojects, namely, the Beijing-Shanghai High-speed Rail, Three Gorges Dam, and Hong Kong-Zhuhai-Macao Bridge. The study adopted mixed research methods, involving literature review, case studies, and expert interviews, to identify 11 driving factors that were grouped into five categories, namely, project environment, construction capabilities, organization, positive culture and behavior, and re-equipment for sustainable development.

Xu and Zou investigated the state of play and future directions in applying the system dynamic (SD) method in construction project management research by undertaking a comprehensive review of 105 relevant articles from 1994 to 2018. On the basis of the review findings, the article discussed three future research directions for SD in construction management research, namely, the integration of SD with other methods, uncertainty analysis, and human factor analysis.

To unravel the mechanism of innovation diffusion in megaprojects, Zhang et al. adopted project network theory to model innovation diffusion in megaprojects as intra- and inter-organizational learning processes. Moreover, SD and

Received December 5, 2020

Weihe HUANG

PetroChina Company Limited, Beijing 100007, China

Chunfang LU

China Railway Society, Beijing 100844, China

Dongping FANG ( ( )

School of Civil Engineering, Tsinghua University, Beijing 100084, China

E-mail: fangdp@tsinghua.edu.cn 
fuzzy systems were combined to interpret experts' subject options as quantitative coefficients of the project network model. Three typical network structures were examined under six management scenarios to verify the proposed analytic paradigm.

To understand the relationship between urban redevelopment and residents' anxiety further, Song et al. conducted a large-scale questionnaire survey in 13 pilot areas in China and gathered statistical data on different anxiety dimensions among residents. The study refined and verified five prominent dimensions of anxiety, namely, housing conditions, monetary compensation, public services, life adaptation, and public participation level, through factor analysis and one-sample $T$-test. Tailored strategies for policymaking and engineering management were proposed to relieve residents' anxiety.

With the aim of improving the management efficiency of megaprojects, Li et al. explored the integration of building information modeling (BIM) and lean construction (LC) in the management of megaprojects. This article described a method that integrates owner-dominated BIM and LC that was developed in a case study of an airport construction project and verified its performance. The results showed that the integration of BIM and LC dominated by the owner could improve management performance and achieve high-quality standards.

Anumba et al. suggested that cyber-physical systems (CPS) have the potential to enhance the delivery and management of construction facilities. Therefore, they introduced the key features of CPS and described how they are ideally suited for addressing a number of problems in the delivery of construction projects. The article outlined the benefits of CPS in various construction applications, including building component placement tracking, temporary structure monitoring, and mobile crane safety.

On the basis of the concept of low-impact development (LID) methods, Zhang and Ariaratnam assessed the effects of adopting green roofs and permeable interlocking concrete pavements on the life cycle costs (LCCs) of drainage systems. The cost information of different construction projects was gathered through interviews of specialty contractors and a review of project documents. The results indicated that the application of LID methods to existing projects can save an average of $27.2 \%$ in LCCs for a 50 -year service life and $18.7 \%$ in LCCs for a 25 -year service life, respectively, in proposed drainage systems.

Kaluarachchi presented the concepts of gray, green, and smart infrastructure and explored their potential to help cities achieve considerable environmental and socioeconomic benefits. The needs, advantages, and applications of integrated smart green infrastructure (SGI) systems were discussed. The methodology adopted multimethod qualitative information review, including literature, case studies, expert interviews, and documentary analysis. Moreover, the study investigated the elimination of silo approaches and the alleviation of the destructions caused by extreme weather events via using interdependent SGI systems.

To understand and predict the effects of forgetting and communication errors on delays in civil infrastructure shutdowns, Sun et al. proposed a modeling and simulation approach based on agent-based modeling, which supports the analytical assessment of outage schedules. This approach can fully consider the cognitive and communication factors involved in handoffs within civil infrastructure outage workflows. The simulation results of a nuclear power plant outage workflow helped verify the delay prediction capabilities of the proposed modeling approach.

Lu et al. proposed a framework to predict regional seismic damage of buildings under a mainshock-aftershock (MS-AS) sequence on the basis of city-scale nonlinear time-history analysis. Specifically, an MS-AS sequencegeneration method was proposed to generate a potential MS-AS sequence that can account for the amplification, spectrum, duration, magnitude, and site condition of a target area. The detailed procedure and advantages of the proposed framework were illustrated in a case study of Longtoushan City, which was damaged during the Ludian earthquake. The results showed that the framework could reasonably and accurately predict regional seismic damage of buildings.

Chen et al. proposed a model to simulate evacuation strategies for vertical ship lift (VSL) during initial fire, which involved the integrated application of stairs and elevators. The model was tested in a case study of the Three Gorges ship lift, in which several evacuation routes were analyzed in accordance with a VSL structure and evacuation times for different evacuation routes were calculated. An objective function corresponding to the minimum vertical evacuation time and simulation model was subsequently developed to obtain a cooperative evacuation plan in consideration of different numbers of evacuees.

The super engineering article submitted by Du and Weng presented a few construction technology innovations developed and tested in the construction of the Quanzhou Bay Bridge. The innovations included new techniques and construction methods, such as a multifunctional well frame for positioning a pile foundation reinforcement cage and an optimized method for formwork configuration of a bearing platform. Smart construction technologies, such as 
sensors, Internet of Things, cloud computer, and other new generation of information technologies, were also adopted for implementing a tower crane safety-monitoring system, process control of an engineering project, and smart management of industry information base data.

In their commentary article, Shen and Xue summarized their research on stakeholder management in the dynamic and complex environment of mega infrastructure projects. The studies analyzed stakeholders' dynamics and the complex nature and evolution of stakeholders' interactions. Two models, namely, a dynamic text-mining model to reveal the change in stakeholder information over time and a longitudinal stakeholder-associated network model to analyze and manage stakeholder complexities, were proposed using the Hong Kong-Zhuhai-Macao Bridge as a case study. Findings from the studies revealed useful information to improve stakeholder management in mega infrastructure projects, such as critical types of stakeholder conflicts and the most affected stakeholder relationships.

Lastly, we would like to appreciate the contribution of all the authors in providing valuable knowledge on this special issue of "city and infrastructure engineering and management". We also extend our gratitude to all the guest editors and reviewers for their time, support, and selfless involvement in the review process.

\section{Guest Editors-in-Chief}

\author{
Weihe HUANG \\ Chunfang LU \\ Dongping FANG
}

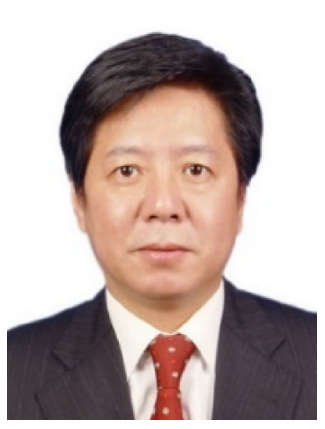

Science and Technology. He established an information-based safety management system for large-scale oil and gas pipeline networks to improve their operation level comprehensively. Dr. Huang won two national first prizes for scientific and technological progress, as well as one special prize and one first prize for scientific and technological progress at the provincial level.

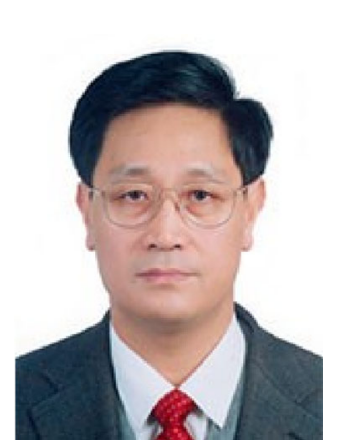

Chunfang LU is an academician at the Chinese Academy of Engineering and an expert on railway engineering technology and management. He is currently the chairman of the China Railway Society and has served as the deputy minister of the Ministry of Railways, the deputy general manager of the China Railway Corporation, and the commander of the Qinghai-Tibet Railway and the Beijing-Shanghai High-speed Railway construction headquarters. Mr. Lu received his bachelor's degree from Southwest Jiaotong University in 1982 and master's degree from Tsinghua University in 2007.

Mr. Lu has long-term experience in railway construction management and scientific and technological innovation, being the actual organizer of China's high-speed railway construction from 2005 to 2016 . He managed the construction of China's high-speed railway network framework, proposed a standardized management model and dynamic construction organization method for high-speed railway construction, organized independent innovation of highspeed railway technology, and established China's high-speed railway technology research, development, and experimental verification system. Mr. Lu won a national first prize for scientific and technological progress. He also authored and published books, such as Standardized Management of Railway Construction Projects and China High-Speed Railway. 


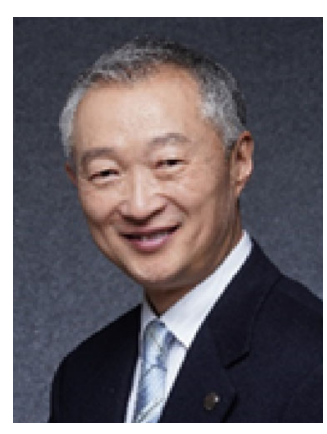

Dongping FANG is a professor at Tsinghua University. He is the Dean of School of Civil Engineering and the Executive Director of the Institute for Future Cities and Infrastructures. Prof. Fang's research field includes construction safety and urban resilience, with more than 200 books and papers published in English, Chinese, and Japanese. He is the former Vice President of CIB (International Council for Research and Innovation in Building and Construction) and the chair of its program committee. He has been sitting on boards and committees of many international and national organizations of government, industry, and academics. He has been honored as visiting professor in Australia, Sweden, and the UK and invited as keynote speaker for many international conferences, such as CIB World Building Congress and Urban Transitions Global Summit. 